\title{
CLINICAL COMPARISON OF AUTOMATED AND MANUAL KERATOMETRY IN PRE-OPERATIVE OCULAR BIOMETRY
}

\author{
PALANISWAMY SUNDERRAJ \\ Southport
}

\begin{abstract}
SUMMARY
Corneal measurements, using the manual (Topcon OM-4) and automated (Canon RK-1) keratometers was performed on 104 eyes of 104 patients undergoing cataract and implant surgery to assess the role of automated keratometry in pre-operative ocular biometry. Four eyes of four patients were excluded from statistical analyses for various reasons. The time taken to perform automated keratometry was a mean of 61 (SD 21) seconds compared to 205 (SD 37) seconds for manual keratometry; the difference was statistically significant $(p<0.001)$. In terms of the various keratometry values compared, mean $K$ (corneal refractive power), flattest $K$, steepest $K$, astigmatism and the axis of astigmatism, $65 \%$ to $75 \%$ of the cases on automated keratometry were within 0.26 dioptres or $11^{\circ}$ of manually determined values; the difference was statistically significant $(\mathrm{p}<0.001)$. Although automated keratometry was significantly quicker than manual keratometry, we continue to use manual keratometry values for intraocular lens power calculations as the accuracy demonstrated by automated keratometry was considered inadequate for this purpose.
\end{abstract}

Manual keratometry (MK) has been widely used in ophthalmic practice for various purposes including pre-operative ocular biometry for the calculation of intraocular lens (IOL) power. Automated keratometers have been introduced recently and have been shown to be as accurate as MK in healthy volunteers ${ }^{1.2}$ and contact lens wearers. ${ }^{3.4}$ Although, Jarvis et al. ${ }^{1.2}$ in a study of ten healthy volunteers found automated keratometry (AK) to be quicker than $\mathrm{MK}$, the use of automated $\mathrm{AK}$ in pre-operative ocular biometry for the calculation of implant power is controversial. Lusby et $a l .{ }^{5}$ considered the accuracy of AK inadequate for this purpose while Knorz et al. ${ }^{6}$ concluded that AK could be a useful alternative to MK. Both the above studies $^{5.6}$ involved the Humphrey autokeratometer; comparable published information is not available for the Canon RK-1 autorefkeratometer.

Correspondence to: Mr. P. SunderRaj FRCS, Department of Ophthalmology, District General Hospital, Southport PR8 6NJ.
This study investigates firstly if $\mathrm{AK}$ using the Canon RK-1 autorefkeratometer is quicker than MK using the Topcon OM-4 ophthalmometer and secondly the accuracy of $\mathrm{AK}$ relative to $\mathrm{MK}$ in patients undergoing cataractimplant surgery to evaluate the role of $\mathrm{AK}$ in pre-operative ocular biometry.

\section{PATIENTS AND METHODS}

\section{Instruments}

The Canon RK-1 autorefkeratometer combines both automated refraction and automated keratometry in one instrument. This instrument measures refraction in the ' $R$ ' mode, keratometry in the ' $\mathrm{K}$ ' mode and both keratometry and refraction in the ' $\mathrm{K}-\mathrm{R}$ ' mode.

In the keratometry mode, the source of measurement is a flash tube which creates a circular ring mire in the cornea. The mire image is reflected on to the position detector which is located in a radial arrangement around the optical axis of the keratometer. The radius of the cornea is determined from the size of the reflection, the astigmatism of the cornea from its reflected ellipticity and the direction of the astigmatic axis from the direction of the reflected axis.

The corneal radii are measured and specified to the nearest $0.01 \mathrm{~mm}$ or 0.12 dioptres (D) assuming the refractive index of the cornea to be 1.3375 . The astigmatic axis is measured in $1^{\circ}$ increments between $1^{\circ}$ and $180^{\circ}$. The measurement range of the radius of curvature of the cornea extends from $5.8-9.5 \mathrm{~mm}(35.5-58 \mathrm{D}$ in corneal refractive power).

$\mathrm{AK}$ is performed by instructing the patient to look at the eye fixation target, observing the corneal image of the circular ring mire in the built-in television monitor and focusing it with the joystick to obtain a sharp mire image. The circular ring target is then aligned with the mire image and the measurement button pressed to obtain the keratometry values. Any number of such measurements may be performed. The data displayed can be printed out, if necessary. If three or more measurements have been performed, the software within the keratometer automatically calculates and prints the most reliable or 'standard' values from the last 3-5 data. 
When measurement is not possible due to improper alignment, droopy eyelids or inability to keep the eyes still, the signal 'ERROR' is displayed to indicate that remedial action is necessary. Measurement is not possible if the mire image is irregular due to irregular astigmatism or severe corneal disease and if the patient's eye is out of the measuring range.

The Topcon OM-4 ophthalmometer is a Sutcliff type one-position keratometer in which two mire images on the cornea are aligned using vertical and horizontal knobs to measure the radius of curvature of the vertical and horizontal axis respectively. If corneal astigmatism is present, the mire images are displaced and the axis rotating handle must be turned to eliminate the displacement and locate the axis of astigmatism.

The corneal radii can be measured to the nearest $0.01 \mathrm{~mm}$ or $0.125 \mathrm{D}$. The astigmatic axis is measured in $1^{\circ}$ increments between $1^{\circ}$ and $180^{\circ}$. The measurement range of the radius of curvature of the cornea extends from 5.5$12 \mathrm{~mm}$ (28-60 D in corneal refractive power).

\section{Patients}

This was a prospective study carried out on patients who were admitted for extracapsular cataract extraction with posterior chamber lens implantation. The eye which was to be operated was studied. The study protocol allowed for only one eye per patient to be included in the study.

\section{Methods}

The Topcon OM-4 ophthalmometer and the Canon RK-1 autorefkeratometer were calibrated as recommended by the manufacturers prior to the study. Both $\mathrm{MK}$ and $\mathrm{AK}$ were performed by the same investigator (PSR) on all the study patients. To avoid bias, MK was performed first followed by AK. Both MK and AK were each performed three times in the eyes studied.

The time taken to perform keratometry was estimated, using an electronic stop watch, from the time the patients' chin was placed on the slit-lamp chin rest. The end point in $\mathrm{AK}$ was completion of the data print out; in MK, the average keratometry values had to be calculated using a Casio fx-82 B scientific calculator and noted.

The accuracy of AK was compared with $\mathrm{MK}$, assuming the latter to be the correct value. The keratometry values compared were, in dioptres, mean $\mathrm{K}$ (corneal refractive power), steepest $K$, flattest $K$ and astigmatism (the difference between maximum and minimum corneal refractive power in the two axes) and in degrees, the axis of astigmatism.

\section{Statistical analysis}

The difference between AK and MK was assessed using (i) Standard error of the difference between means on the mena time taken (in seconds) to perform keratometry and (ii) Chi-squared $\left(\chi^{2}\right)$ test on the number of eyes on $\mathrm{AK}$ which were within $0.26 \mathrm{D}$ of manually determined mean $\mathrm{K}$, steepest $\mathrm{K}$, flattest $\mathrm{K}$ and astigmatism and within $11^{\circ}$ of manually determined astigmatic axis.

\section{RESULTS}

Of the 104 patients eligible for the study, neither MK nor $\mathrm{AK}$ of the eye undergoing surgery was possible in two patients. This was due to dementia and lack of co-operation in one patient and osteoporosis-related kyphoscoliosis in the other. In another two patients, AK could not be performed but MK was possible with great difficulty. One of these patients could not keep the eyes still while the other had head tremor. All four patients were excluded leaving 100 eyes of 100 patients for analysis.

The study included 59 females and 41 males. The age range was 61-94 years with a mean of 76 (SD 8) years. There were 53 left and 47 right eyes.

$\mathrm{AK}$ with the Canon RK-1 was performed in a mean of 61 (SD 21) seconds per eye with a range of 39 to 176 seconds. MK with the Topcon OM-4 ophthalmometer took a mean of 231 (SD 41) seconds per eye with a range of 162 to 331 seconds. The difference was statistically significant $(\mathrm{p}<0.001)$.

The accuracy of $\mathrm{AK}$ considering MK to be the correct value is shown in Table $I$. The average corneal refractive powers determined by $\mathrm{AK}$ for mean $\mathrm{K}$, steepest $\mathrm{K}$, and flattest $K$ were weaker than those determined manually. The difference between $\mathrm{AK}$ and $\mathrm{MK}$ was statistically significant $(p<0.001)$ when the number of eyes on $A K$ within $0.26 \mathrm{D}$ of manually determined mean $\mathrm{K}$, steepest $\mathrm{K}$, flattest $\mathrm{K}$, and astigmatism and within $11^{\circ}$ of manually determined axis of astigmatism were compared.

\section{DISCUSSION}

The recent introduction of automated keratometry has challenged the sole reliance of clinical keratometry on the manual measurement of corneal curvature. In this study of patients undergoing cataract-implant surgery. AK with the Canon RK-1 was at least three times faster than MK with the Topcon OM-4 ophthalmometer and resulted in a saving of about 2.5 minutes per eye. Additionally, the clinical impression was that the $\mathrm{AK}$ was easier to perform and required less skill compared with MK. Similar observations have been reported in healthy volunteers.'

Previous studies ${ }^{5.6}$ on the use of AK in pre-operative ocular biometry and calculation of implant power arrived at differing conclusions. Lusby et al., ${ }^{5}$ using the Humphrey Autokeratometer in 497 consecutive eyes, thought that its accuracy was probably not adequate for implant

Table I. Comparison of corneal refractive powers obtained by automated and manual keratometry (cumulative percentage of patients)

\begin{tabular}{|c|c|c|c|c|c|}
\hline & \multirow{2}{*}{$\begin{array}{c}<6^{\circ} \\
<(0.126 \mathrm{D}\end{array}$} & \multirow{2}{*}{$\begin{array}{c}<11^{\circ} \\
<0.26 \mathrm{D}\end{array}$} & \multirow{2}{*}{$\begin{array}{c}<21^{\circ} \\
<(0.51 \mathrm{D}\end{array}$} & \multicolumn{2}{|c|}{ OM4-RKI } \\
\hline & & & & Average & SD \\
\hline Mean K (D) & 42 & 74 & 98 & 0.11 & 0.27 \\
\hline Flattest K (D) & 39 & 65 & 95 & 0.13 & 0.29 \\
\hline Steepest K (D) & 45 & 74 & 97 & $0 .(07$ & 0.26 \\
\hline Astigmatism* & & & & & \\
\hline (D) & 51 & 75 & 95 & 0.08 & 0.23 \\
\hline Axis (degrees) & 41 & 65 & 96 & $6.6^{\circ}$ & $12.2^{\circ}$ \\
\hline
\end{tabular}

Key: D = dioptres; OM-4 = Topcon OM-4 ophthalmometer; RK-1 = Canon RK- 1 autorefkeratometer; $\mathrm{SD}=$ Standard deviation; $\mathrm{K}=$ Corneal refractive power; ${ }^{*}=$ the difference between maximum and minimum corneal refractive powers in the two axes of astigmatism. 
power calculations. However, Knorz et al. ${ }^{6}$ studying the same instrument in 53 eyes of 37 patients claimed that $\mathrm{AK}$ could be a useful alternative to $\mathrm{MK}$ in the pre-operative determination of intraocular lens power.

Our results with the Canon RK-1 autorefkeratometer show that the average difference between $\mathrm{AK}$ and MK was 0.11 (SD 0.27) D for the mean corneal refractive power, the value which is used in the calculation of intraocular implant power. Although this difference appears negligible, Table I shows that on AK $26 \%$ of the eyes had a difference of $>0.25 \mathrm{D}$ in mean corneal refractive power determined manually; this difference was statistically significant $(p<0.001)$. It has been shown that for an error of only $0.25 \mathrm{D}$ in the measurement of corneal refractive power, assuming that the axial length was measured accurately, the error in calculated implant power could vary from 0.28 (SD 0.04) D to 0.31 (SD 0.05) D depending on the actual axial length and corneal curvature of a given eye. $^{7}$ If the simultaneous error in axial length measurement was as small as $0.1 \mathrm{~mm}$, a $0.25 \mathrm{D}$ error in the measurement of corneal refractive power would be associated with an error in calculated implant power of between 0.53 (SD 0.04) D and 0.82 (SD 0.37) D depending on the actual axial length and corneal curvature of a given eye. ${ }^{7}$ Also, we found that MK could be performed in some patients in whom AK was not possible. Hence, we continue to use manual keratometry for pre-operative ocular biometry and the determination of intraocular lens power.

In the calculation of implant power, 'optimising' the constants used in the theoretical and empirical formula has resulted in improved predictive accuracy for the surgeon concerned. ${ }^{8-10}$ This is because the value of the constants used ( ' $A$ ' constant in the empirical SRK formula and the estimated post-operative anterior chamber depth 'ACD' in the theoretical formulae) depends on surgeon-specific variables like the method of ocular biometry, the surgical technique and the type and style of intraocular lens implanted. ${ }^{11.12}$ Hence, it may be possible to use AK in the calculation of implant power without adversely affecting accuracy by 'optimising' the constants used in the implant power calculation formulae. Since the Canon RK-1 measurement of mean corneal refractive power was on average weaker than that measured manually, the value of the constants used in the implant power calculation formulae would have to be increased relative to that used with MK to achieve equally accurate prediction of post-implant refraction. This subject is currently under investigation.

In summary, automated keratometry was quicker and easier to perform than manual keratometry although, the accuracy of automated keratometry, as demonstrated, was considered inadequate for the calculation of implant power.

We thank Anne E. Lewis for help in carrying out this study and K. Devi SunderRaj for secretarial assistance.

Key words: Cataract surgery, Implant surgery, Ocular biometry, Keratometry: automated, manual.

\section{REFERENCES}

1. Jarvis VN, Levine R, Asbell PA: Manual versus automated keratometry: a comparison. CLAO J 1987, 13: 235-7.

2. Ehrlich DL and Tromans C: The Canon RK-1: keratometry mode evaluation. Ophthal Physiol Opt 1990, 10: 97.

3. Halberg GP, Almeida EE, San Flippo DM: A new autokeratometer. Contact Intraocular Lens Med J 1982, 8: 173-80.

4. Nakada S, Tanaka M, Nakajima A: Comparison of automated and conventional keratometry. Am J Ophthalmol 1984, 97: 776-8.

5. Lusby FW, Franke JW, McCaffery JM: Clinical comparison of manual and automated keratometry in a geriatric population. CLAO J 1987, 13: 119-21.

6. Knorz MC, Kohl M, Trinkmann R: Automatische Biometric and Keratometric in Verglech zur manuellen technik. Fortschr Ophthalmol 1989, 86: 157-8.

7. McEwan JR, Massengill RK, Friedel SD: The effect of keratometer and axial length measurements on primary implant power calculations. J Cataract Refract Surg 1990, 16: 61-70.

8. Dang MS and SunderRaj P: SRK II formula in the calculation of intraocular lens power. Br J Ophthalmol 1989, 73: $832-6$.

9. SunderRaj P: Calculation of intraocular lens power. J Cataract Refract Surg 1990, 16: 387-8.

10. Dang MS and SunderRaj P: Calculation of the power of posterior chamber intraocular implants. Afro-Asian J Ophthalmol 1990, 8: 142-5.

11. Retzlaff J, Sanders DR, Kraff MC: A manual of implant power calculation Oregon Medford 1982.

12. Richards SC, Olson RJ, Richards WL, Brodstein RS, Hale PN: Clinical evaluation of six intraocular lens calculation formulas. Am Intraocul Implant Soc J 1985, 11: 153-8. 